\title{
Attributes of Water Additives Affect Postharvest Needle Retention of Fraser Fir
}

\author{
L.E. Hinesley ${ }^{1}$ and Sylvia M. Blankenship ${ }^{1}$ \\ Department of Horticultural Science, North Carolina State University, \\ Raleigh, NC 27695-7609
}

Additional index words. Abies fraseri, Christmas trees, molarity, $\mathrm{pH}$, solute, pulse duration

Abstract. Cut branches of Fraser fir [Abies fraseri (Pursh) Poir.] were subjected to solutions with different molarity, $\mathrm{pH}$, and solutes. Citrate-phosphate and Na-phosphate buffers induced heavy needle loss at concentrations as low as $10 \mathrm{~mm}$, whereas needle loss was negligible for MES buffer, sucrose solutions, and distilled water. Needle drop increased in response to higher solute concentration and/or greater duration of exposure. Needle loss was almost $100 \%$ at $\mathrm{pH} \mathrm{3.0}$ and 9.0, but minimal at pH 6.0 and 7.0. Chemical name used: 2-(N-morpholino) ethanesulfonic acid (MES).

It is common in the floral trade to treat cut flowers with chemical additives to enhance shelf life (Halevy and Mayak, 1981). Constituents of commercial preparations include ionic salts, such as $\mathrm{CaCl}_{2}, \mathrm{MgCO}_{3}$, and $\mathrm{KC}$ ], as well as acidifying agents, carbon sources, and fungicides. A possible use for such products is in postharvest keeping of cut Christmas trees. Even though additives in the irrigation water of displayed Christmas trees are normally of little or no benefit (Ahrens and Stephens, 1975; Montano and Proebsting, 1985; Van Wagner, 1963), there is a continuing interest in identifying substances that might have a preserving effect on cut Christmas trees.

Fraser fir is a valuable Christmas tree species in the United States and Canada. It is not known how postharvest needle retention of Fraser fir is affected by water additives. Therefore, the objective of this research was to determine needle loss of cut Fraser fir branches in response to $\mathrm{pH}$, molarity, type of solute, and pulse duration.

General procedures. Experiments were conducted in Fall 1988 and 1989 using material from a group of 15-year-old, nonsheared Fraser fir growing at Crossnore, N.C. Similar field and laboratory procedures were used throughout. Owing to space limitations

Received for publication 25 May 1990. The research reported in this publication was funded by the North Carolina Agricultural Research Service. We thank Donna Ellsworth and Layne Snelling for technical assistance. The cost of publishing this paper was defrayed in part by the payment of page charges. Under postal regulations, this paper therefore must be hereby marked advertisement solely to indicate this fact.

${ }^{1}$ Associate Professor. and the many treatments, branches were used rather than whole trees. This gave a better experimental design because the number of branches from each tree equaled the number of treatments, with one branch assigned to each treatment. This approach eliminated genetic variation in the comparison of treatments and indicated variability among trees. Within each tree, branches were selected for uniformity in size and vigor and consisted of second-order laterals 20 to $30 \mathrm{~cm}$ long from the second node of first-order laterals $\approx 2 \mathrm{~m}$ above the ground.

Following severance, branches were immediately placed upright with ends in water, transported to Raleigh, N. C., and stored overnight at $5 \mathrm{C}$. The next morning, after removing 2-year-old foliage, the base of each branch was recut under water, and individual branches were placed upright in containers with $150 \mathrm{ml}$ of the treatment solutions. Final branch length was 20 to $30 \mathrm{~cm}$. Buffers were prepared according to Gomori (1955). Containers were sealed to prevent evaporation, and covered or painted to block entrance of light.

Experiments were conducted at $20 \pm 2 \mathrm{C}$ on a large table, using a randomized complete block design. Solutions were renewed weekly. Every experiment included a distilled water control with an initial $\mathrm{pH}$ of 5.5. Needle loss was evaluated weekly by lightly rubbing foliage with fingers. Preliminary experiments, lasting up to 4 weeks, showed that most needle drop occurred in the first week, so later experiments were normally of 2 or 3 weeks duration. Detached foliage was dried to constant weight at $65 \mathrm{C}$ and weighed. After each experiment, remaining foliage was removed, dried as described previously, and weighed to determine percent needle loss. Where appropriate, regression analysis was performed (SAS Institute, 1985).

Effect of pH (Expt. 1). A preliminary experiment with $100 \mathrm{~mm}$ citrate-phosphate buffers ( $\mathrm{pH}$ levels of 2.5 to 5.5) resulted in heavy needle loss in all treatments except distilled water. In the next experiment (1A), branches were collected from six trees on 12 Jan. 1989 and allocated to citrate-phosphate buffers ( $\mathrm{pH}$ levels of 3.0, 4.0, and 5.0) and Na-phosphate buffers (pH levels of 6.0,7.0, and 8.0), all at $5 \mathrm{~mm}$. More than one type of buffer was necessary to obtain a wide range of $\mathrm{pH}$. The experiment lasted 4 weeks.

Experiment 1A was repeated with 20 replications (trees), beginning 15 Nov. 1989 (Expt. 1B). Five pH levels were used, all at $5 \mathrm{~mm}$ of buffer: 3.0,5.0, 6.0, 7.0, and 9.0. The two lowest $\mathrm{pH}$ treatments used potassium acid phthalate-hydrochloric acid buffer; the two middle values were for Na-phosphate buffers, and the highest $\mathrm{pH}$ was achieved with boric acid-borax buffer. The duration was 2 weeks.

Type of buffer or solute (Expt. 2). Branches were collected from six trees on 25 Oct. 1988 (Expt. 2A) and placed in the following solutions: 1) distilled water, 2) $1.0 \mathrm{~mm} \mathrm{Na}$ phosphate buffer, 3) $10 \mathrm{~mm}$ Na-phosphate buffer, 4) $100 \mathrm{~mm}$ Na-phosphate buffer, or 5) 100 mM MES buffer (Good et al., 1966). All buffers had a $\mathrm{pH}$ of 6.0. The experiment lasted 2 weeks.

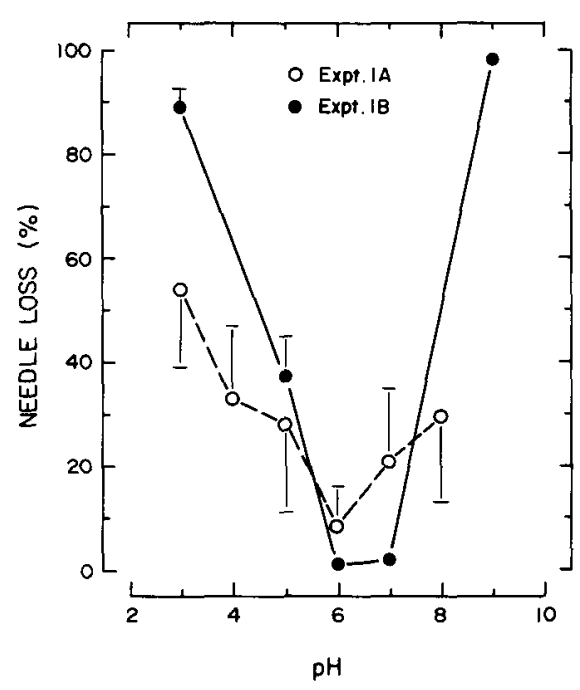

Fig. 1. Effect of $\mathrm{pH}$ (buffer concentration $=5$ $\mathrm{mm}$ ) on needle loss of branches of Fraser fir. Experiment $1 \mathrm{~A}(\mathrm{O}) ; \mathrm{n}=6$, duration $=4$ weeks. Experiment 1B ( ); $\mathrm{n}=20$, duration $=2$ weeks. Vertical bars $=$ SE. The regression for needle drop (NL, \%) in Expt. 1B was: NL = $357.7-116.6(\mathrm{pH})+9.69(\mathrm{pH})^{2} ; R^{2}=0.74$. 


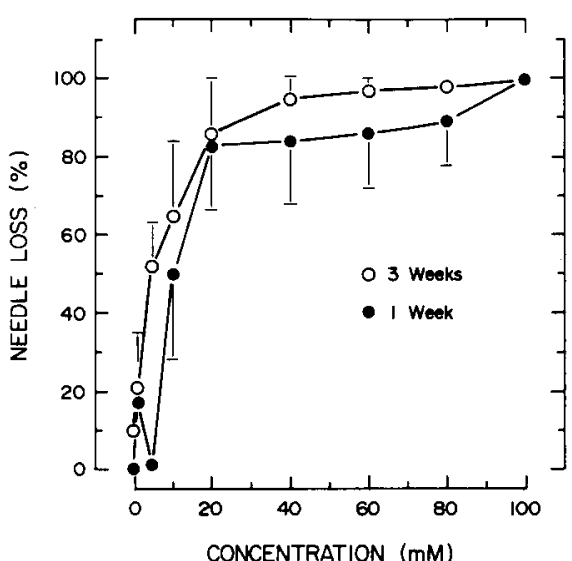

Fig. 2. Needle loss from branches of Fraser fir after 1 and 3 weeks in citrate-phosphate buffers $(\mathrm{pH}=5.0)$ of different molarity (Expt. 3A). (๑) One week, ( ○ 3 weeks. Vertical bars = $\mathrm{SE} ; \mathrm{n}=6$.

Another set of branches was collected from 10 trees on 12 Dec. 1989 (Expt. 2B) and subjected to sucrose solutions $(10,20,40$, 80 , and $160 \mathrm{~mm}$ ) and Na-phosphate buffers (10, 20, 40, and $80 \mathrm{~mm})$, all at $\mathrm{pH} 6.5$. Needle loss was determined after 2 weeks.

Molarity and pulse duration (Expt. 3). After initial results in Expt. 2 suggested a critical concentration between 10 and $100 \mathrm{~mm}$, branches were collected from six trees on 9 Nov. 1988 (Expt. 3A) and subjected to citrate-phosphate buffers $(\mathrm{pH}=5.0)$ at concentrations of $1,5,10,20,40,60,80$, or $100 \mathrm{~mm}$. The experiment lasted 3 weeks. Because the effect of concentration appeared to respond to pulse duration, another experiment (3B) was conducted using $0,5,10$, 20, 40, and $80 \mathrm{~mm} \mathrm{Na-phosphate} \mathrm{buffers}$ ( $\mathrm{pH}=6.0)$ in factorial combinations with pulse durations of $0.5,1,2,4$, and 8 days. Branches were collected from 10 trees on 17 Oct. 1989. Following the designated pulse time, solutions were replaced with distilled water. The experiment lasted 2 weeks.

There was a quadratic relationship between $\mathrm{pH}$ and needle drop, with the minimum at $\mathrm{pH}=6.0$ to 7.0 (Fig. 1), but needle drop was heavy at $\mathrm{pH} 3.0$ or 8.0 to 9.0. Needle drop averaged only $3 \%$ in distilled water at $\mathrm{pH}$ 5.5. Branches apparently died at $\mathrm{pH} 9.0$ (boric acid buffer), as evidenced by brown or bronze-green foliage. At $\mathrm{pH}$ 3.0, most abscised needles were dark green. Not all trees had heavy needle loss at $\mathrm{pH}$ 3.0, and several were adversely affected at pH 5.0.

Solution concentration had a crucial effect on needle drop. Sodium-phosphate or citrate-phosphate buffers at $100 \mathrm{~mm}$ always caused extensive needle drop (Figs. 2-4), usually within the first week. Needle loss averaged $\approx 55 \%$ at $10 \mathrm{~mm}$ (Figs. 2 and 3 ) and was negligible at $1.0 \mathrm{~mm}$. MES buffer at $100 \mathrm{~mm}$ (data not shown) and sucrose at concentrations up to $160 \mathrm{mM}$ (Fig. 3) resulted in essentially no needle loss.

In addition to the effect of concentration, needle loss was also affected by duration of treatment (Fig. 4). Branches subjected to 80

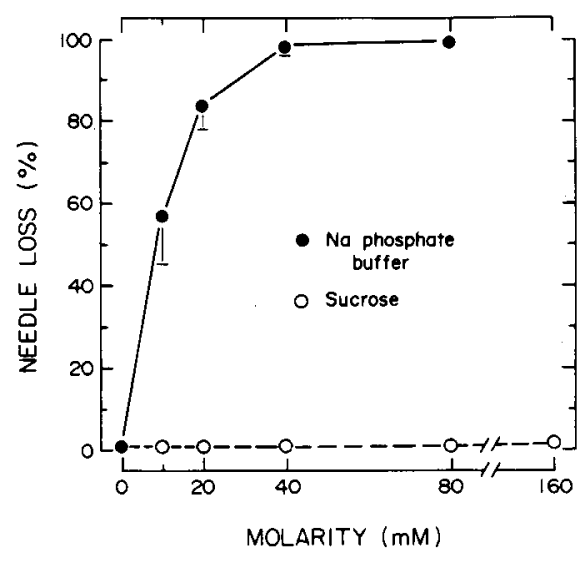

Fig. 3. Needle loss (NL, \%) of branches of Fraser fir subjected to Na-phosphate buffer (0) and sucrose solutions ( $\mathrm{O}$ ) of varying molarity $(\mathrm{M})$; $\mathrm{pH}=6.5$ (Expt. 2B). Vertical bars = SE; $\mathrm{n}$ $=10$. The model for Na-phosphate buffer was: $\mathrm{NL}=100[1-\exp (0.087 \mathrm{M})] ; R^{2}=0.95$.

mM Na-phosphate buffer for 4 days lost $100 \%$ of their needles, compared to $10 \%$ needle drop following a 0.5-day pulse. A similar effect, but less dramatic, was evident for 40and 20-mm solutions. For most durations of exposure, reducing the molarity decreased needle drop. A pulse of at least 4 days was required to affect needle loss at 5 and 10 $\mathrm{mM}$.

There was great variation among trees in response to molarity and $\mathrm{pH}$. This was most evident during the first week after initiation of treatments, particularly at concentrations $\leq 20 \mathrm{~mm}$ In one experiment, several trees lost $70 \%$ or more of their foliage in 3 days, compared to one tree that lost only $11 \%$. With time, especially after 3 to 4 weeks, trees that initially were more tolerant of higher solute concentrations exhibited accelerated needle drop.

Similar variation among trees was apparent for different $\mathrm{pH}$ levels. For example, at $\mathrm{pH} 3.0$, one tree experienced $10 \%$ needle loss, compared to $100 \%$ needle loss in several others. Based on these results, and assuming that the uptake of solutes was about equal in all samples, it might be practical to screen clones for tolerance to additives as well as acidity.

Our conclusions are limited with respect to $\mathrm{pH}$ because treatment effects were confounded with buffers; no one buffer could cover such a wide $\mathrm{pH}$ range. However, needle loss at $\mathrm{pH} 3.0$ was considerably greater than at pH 5.0 (Fig. 1); both treatments were derived from the same buffer. The rapid demise of branches at $\mathrm{pH} 9.0$ might have resulted from $\mathrm{B}$ toxicity. We conclude that a $\mathrm{pH}$ near 6.0 is least likely to accelerate needle drop.

Currently, we cannot explain the sensitivity to phosphate buffer because the lower concentrations ( 1 to $10 \mathrm{~mm}$ ) are normally nonphytotoxic to most plant tissue (Scopes, 1982). Phosphate buffers can precipitate polyvalent cations and act as metabolizes or inhibitors in some systems (Good et al., 1966). In these experiments, transpiration was

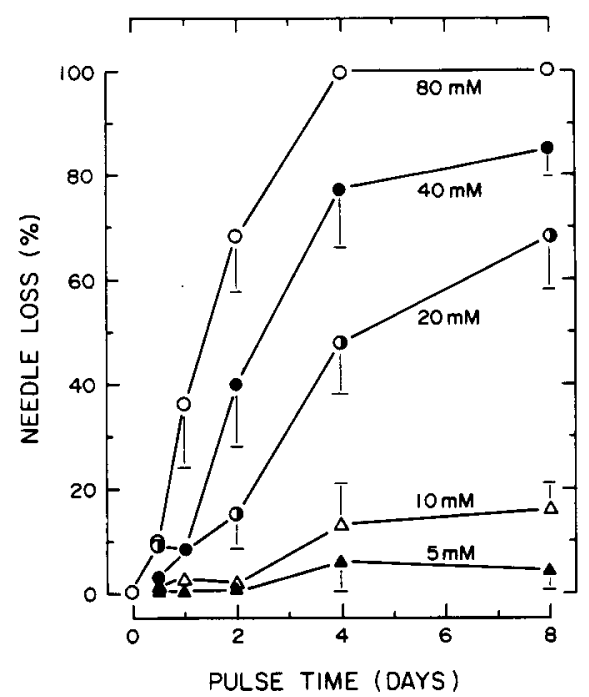

Fig. 4. Needle loss of branches of Fraser fir in Na-phosphate buffers $(\mathrm{pH}=6.0)$ in response to molarity (mM) and duration of exposure (D = days) (Expt. 3B). ( $\boldsymbol{\Delta}) 5 \mathrm{~mm},(\Delta) 10 \mathrm{~mm}$, ( ○ ) $2.0 \mathrm{~mm},(\bigcirc) 40 \mathrm{~mm},(\bigcirc) 80 \mathrm{~mm}$. The regression model was: $\mathrm{Y}=-3.14+0.38(\mathrm{M})$ $+2.56(\mathrm{D})+0.13(\mathrm{M} * \mathrm{D}) ; R^{2}=0.60$. Measured after 2 weeks. Vertical bars $=\mathrm{SE} ; \mathrm{n}=$ 10 .

not measured, and it is unknown how much solute was translocated to the foliage.

Certain ions, even at very low concentrations, can adversely affect postharvest life (Lohr and Pearson-Mires, 1990). Knowing the sensitivity of Fraser fir to different ions will help in attempts to develop preservatives for cut Christmas trees. Many sources of potable water possibly contain sufficient levels of inorganic ions to affect needle loss of some trees. The most reliable approach is to display cut trees in deionized water.

\section{Literature Cited}

Ahrens, J.F. and G.R. Stephens. 1975. The effects of additives on freshness and flammability of Christmas trees. Connecticut Agr. Expt. Sta. Bul. 760.

Gomori, G. 1955. Preparation of buffers for use in enzyme studies, p. 138-156. In: S.P. Colowick and N.O. Kaplan (eds.). Methods in enzymology. vol. 1. Academic, New York.

Good, N. E., G.D. Winget, W. Winter, T.N. Connolly, S. Izawa, and R.M.M. Singh. 1966. Hydrogen ion, buffers for biological research. Biochem. 5:467-477.

Halevy, A.H. and S. Mayak. 1981. Senescence and postharvest physiology of cut flowers. Part 2. Hort. Rev. 3:59-143.

Lohr, V.I. and C.H. Pearson-Mires. 1990. Damage to cut roses from fluoride in keeping solutions varies with cultivar. HortScience 25:215216.

Montano, J. and W.M. Proebsting. 1985. OSU tree keepability report. Northwest Lookout (Northwest Christmas Tree Assoc.) 18(3):5859, 61-63.

SAS Institute, Inc. 1985. SAS User's guide: Statistics, version 5 ed. SAS Inst., Inc., Cary, N.C.

Scopes, R.K. 1982. Protein purification. Springer-Verlag, New York.

Van Wagner, C.E. 1963. Flammability of Christmas trees. Canada Dept. For. Publ. 1034. 